\title{
Cervical cancer screening: knowledge, health perception and attendance rate among Hong Kong Chinese women
}

This article was published in the following Dove Press journal:

International Journal of Women's Health

8 July 2010

Number of times this article has been viewed

\section{Sharron SK Leung' Ivy Leung ${ }^{2}$}

'School of Nursing, Li Ka Shing Faculty of Medicine, The University of Hong Kong; ${ }^{2}$ Quality Healthcare Medical Services, Hong Kong
Correspondence: Sharron SK Leung School of Nursing, Li Ka Shing Faculty of Medicine, The University of Hong Kong, 4/F, William MW Mong Block, 2 I Sassoon Road, Pokfulam, Hong Kong

Tel +852 28192626

Fax +852 28726079

Email sleung@hku.hk
Purpose: Cervical cancer screening has been consistently shown to be effective in reducing the incidence rate and mortality from cervical cancer. However, cervical screening attendance rates are still far from satisfactory in many countries. Strategies, health promotion and education programs need to be developed with clear evidence of the causes and factors relating to the low attendance rate. The study aims to assess the prediction of cervical screening attendance rate by Chinese women's knowledge about cervical cancer and cervical screening as well as their perception of health.

Patients and methods: A survey with self-reported questionnaires was conducted on 385 Chinese women recruited from a community clinic in Hong Kong. Participants were Chinese women, Hong Kong residents, aged 18-65 years, able to read Chinese or English, and were not pregnant.

Results: Women aged 37 years or less, with at least tertiary education, who perceived having control over their own health and had better knowledge on risk factors, were more likely to attend cervical cancer screening. Many participants had adequate general knowledge but were unable to identify correct answers on the risk factors.

Conclusion: Health promotion efforts need to focus on increasing women's knowledge on risk factors and enhancing their perceived health control by providing more information on the link between screening and early detection with lower incidence rates and mortality from cervical cancer.

Keywords: cervical screening attendance, cervical cancer, health perception and knowledge, perceived health control, Chinese

Cervical cancer is the second most common cancer among women, with about 500,000 new cases and 250,000 deaths each year worldwide. ${ }^{1}$ The progression of lesions to invasive cancer is slow and most lesions are asymptomatic but can be detected by cervical screening. ${ }^{2}$ Early detection of cervical cancer can lead to a good prognosis resulting in a decrease in the mortality and health care costs; if left untreated, the individual suffers and there are significant adverse effects on the families and the community. ${ }^{3}$

Cervical screening attendance is likely to be affected by knowledge of cervical Pap smear screening, the risk factors of cervical cancer, and health perception. Although these factors have been widely studied among North American patients, very limited studies are reported among Asian and particularly Chinese. It is not known whether these factors contribute to the low cervical screening rates in many other countries. This study probes the link between cervical screening rate against Chinese women's 
knowledge about cervical cancer and cervical screening as well as their perception of health.

Several countries in North America and Europe have successfully achieved high screening rates and significant reductions of $20 \%-60 \%$ in cervical cancer mortality with population-wide screening. ${ }^{4}$ However, studies showed that the cervical screening rate was low in many other populations. ${ }^{5,6}$ Studies suggested that unscreened women were at high risk of cervical cancer and thus researchers continued to investigate different reasons for non-screening. .,8 $^{7}$

In Hong Kong, the estimated percentage of women who have been screened for cervical cancer was 44\% in 1998 and was increased to $60 \%$ after the Department of Health launched a territory-wide cervical cancer screening program in $2004 .^{9}$ Cervical cancer was the seventh most common cancer in females in Hong Kong in 2007 with a crude incidence rate of 11 per 100,000 female population. The age-standardized incidence rates in 2000 were higher than those reported in the European Union, England, United States, Canada, and Australia, and age-standardized mortality ranked second highest next to the European Union among these countries. ${ }^{10}$

Research suggests that intrinsic factors influence women's cervical screening rates and this has been reported consistently among different populations including Caucasian, Asian, and Latino-American women. ${ }^{8,11,12}$ Intrinsic factors included women's knowledge, beliefs, and attitudes towards cervical screening and cancer. ${ }^{13}$ Women who received regular checkups and had lower perceived barriers were more likely to have cervical screening. ${ }^{5}$

Other studies have reported a relationship between cervical screening and demographic variables. People in younger age groups and with higher education levels were found to have greater awareness of cervical screening. ${ }^{14}$ Women's choice of not attending cervical cancer screening was complex; ${ }^{8}$ more specific information is needed about what kind of knowledge and what specific health perception determines screening, taking into account the significant demographic factors.

The Department of Health in Hong Kong launched a territory-wide cervical screening program in early $2004 .{ }^{15}$ Since then, the screening rate among women in Hong Kong has been closely monitored through the Behavioral Risk Factor Surveillance System every 6 to 12 months. The target population for cervical screening is women aged 25-64 years who are sexually active or women aged younger than 25 years who have an increased risk profile. For women aged 65 years or more, screening may be discontinued if 3 recent consecutive smears taken within 10 years are normal. The aim of the program is to achieve $60 \%$ screening rate within 3 years after launch and increase to $80 \%$ or more in the longer term, which is in line with international models. However, the statistics in April 2008 showed only $62.6 \%$ of women aged 25 to 64 have taken cervical smear within 3 years, which was only a modest increase compared to the 59.2\% in October 2004.

This study was designed based on the Theory of Reasoned Action (TRA) and the Health Belief Model (HBM). ${ }^{16,17}$ TRA postulates that personal perception may influence the screening rate. An individual's belief will lead to their actual behavior. When people believe their lives and health are under their control, they are more likely to participate in health-promoting activities. HBM proposes that the perception of the severity of illness, susceptibility to illness and its consequences are the factors that predict the likelihood of a person taking recommended preventive health action.

This study investigated the knowledge of cervical cancer and risk factors as well as the perception of health control. The study provides quantitative evidence on the association of knowledge of screening, health perception and cervical screening after controlling for demographic variables. The results of this study provide valuable insights for strengthening the strategic health promotion effort to increase screening rates.

\section{Material and methods \\ Design and sample}

This study used a cross-sectional design. Participants were Chinese women with a Hong Kong Permanent Identity Card who were:

- aged 18-65 years;

- able to read Chinese or English;

- not pregnant.

The study was approved by the Institutional Review Board of The University of Hong Kong.

A total of 379 women were recruited in a private medical center in Hong Kong. All patients who came to the medical center for medical appointments were approached. Eligible participants were invited to participate and the purpose of the study was explained. Those who consented to take part were given a set of questionnaires to be completed while waiting to see the doctors, and these completed questionnaires were returned to the researcher directly. The researcher was available to answer any questions for the participants throughout.

\section{Measures}

A validated scale was used to assess women's health perception, knowledge about cervical screening and the risk factors of cervical cancer. The original questionnaire was developed by Seow and associates in Singapore. ${ }^{18}$ The 
scale was translated into Chinese and used in studies in Hong Kong. ${ }^{13,19,20}$ Minor modifications were made from a telephone survey to a self-administered questionnaire for this study.

The questionnaire consisted of the following sections:

a. health perception and health behavior;

b. general knowledge on cervical screening, cervical cancer and the risk factors;

c. socio-demographic characteristics.

Section A consisted of 11 questions including how the respondents perceived their own health, perceived control over health, their concerns about family/relatives' health and the influence of family/relatives' health.

Section B consisted of 9 items to test the participants on their general knowledge of cervical screening and cervical cancer, and 9 items on the risk factors. Participants rated "agreed", "not agreed", “don't know". Cronbach's alphas were $0.62,0.60$ and 0.63 for general knowledge, knowledge on risk factors and total knowledge scales, respectively.

Section $\mathrm{C}$ consisted of demographics data including age, education level, monthly household income, marital status, number of children, and regular sources of health care.

\section{Data analysis}

Pearson's correlation was examined for the relationships between cervical screening and age, education, income, knowledge, and health perception.

The $\chi^{2}$ test was used to examine the relationships between screening and non-parametric variables.

Differences between screening and non-screening for knowledge were demonstrated by independent $t$-test.

Logistic regression was used to indicate health perception, knowledge, and risk of cervical cancer as well as demographic factors associated with cervical cancer screening. Factors included in the logistic model were age, education, income, perceived health, perceived controlled over health, concerns about family/relatives' health, and health behaviors influenced by their health, general knowledge on cervical screening and cancer, and knowledge on risk factors. The Hosmer and Lemeshow $\chi^{2}$ test of goodness-of-fit was used to test the overall fit of the logistic model.

All statistical analyses were performed using SPSS $^{\circledR}$ version 14.0 with $95 \%$ level of significance.

\section{Results}

\section{Participants characteristics}

A total of 420 women were approached and assessed for eligibility. 385 were eligible and agreed to participate giving a response rate of $92 \%$ and 35 found to be ineligible and/or unwilling to participate. Six participants did not return the questionnaire and hence were excluded. Data from the remaining 379 participants were available for analysis.

The median age of the study participants was in the age group 28-37 years. More than half of the participants ( $n=194$, $51.2 \%$ ) were educated to tertiary or higher level, almost half of them ( $n=183,48.3 \%)$ had received secondary education and only $2(0.5 \%)$ had received no formal education.

$54.4 \%(n=206)$ of the participants were married and $41.4 \%(n=157)$ were single.

Sixty-nine (18.2\%) of the participants had never attended screening and $33(8.7 \%)$ said that they never thought of having such a test.

Table 1 shows the frequencies of health perception on self and families, age and education, and their correlations with cervical screening. Cervical screening was not correlated with age but significantly correlated with education and income.

\section{General knowledge and knowledge on risk factors}

Screening was also significantly correlated with knowledge on cervical screening, cervical cancer and risk factors (Table 1). The mean total knowledge score was higher for screening than non-screening $(t=6.47, P<0.001)$.

Table 2 shows the numbers and percentages of correct and "don't know" answers to each item on general knowledge and knowledge of risk factors. Total knowledge included general knowledge and knowledge of risk factors. Only about one-fifth of the women (19.3\%) received a full score on general knowledge and only $0.3 \%$ had a full score on the risk factors. High percentages of women reported they did not know whether some items were risk factors $(17.9 \%$ to $41.2 \%$ for 5 out of the 9 risk factors).

\section{Health perception}

More than half of the participants $(66.2 \%)$ considered themselves healthy and only $5.5 \%$ reported themselves as not healthy. Less than one-third of the participants $(28.5 \%)$ believed that they did not have control of their health. Very high percentages (95.3\%) were concerned about family or relatives' health and half of the participants reported that their health behaviors were influenced by family or relatives' health. Cervical screening was significantly correlated with health perception except when influenced by family/relatives' health (Table 1).

\section{Factors predict screening rate}

Table 3 shows odds ratios of the predictors on cervical screening with logistic regression. Hosmer and Lemeshow goodness-of-fit 


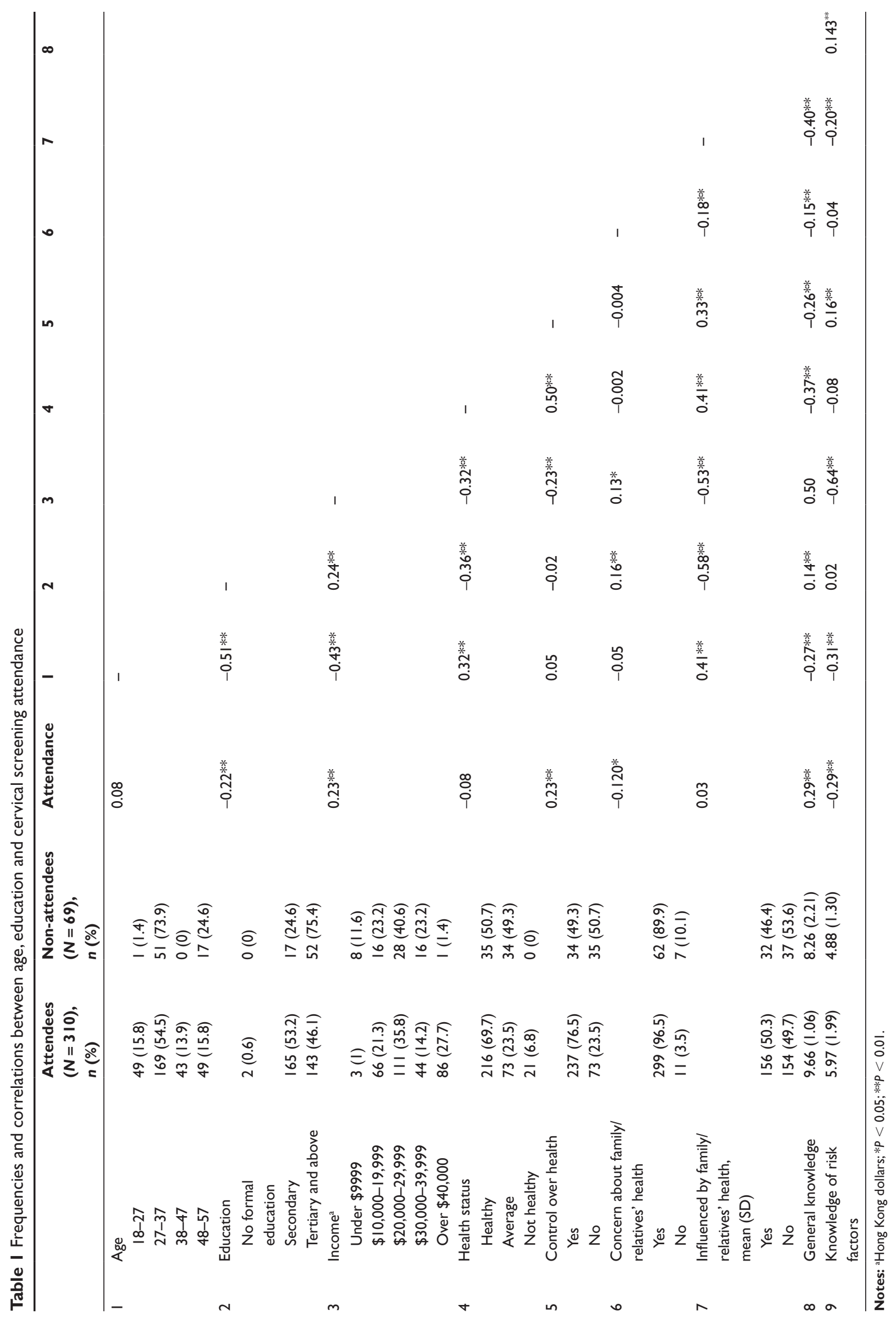


Table 2 Number and percentage of correct and "don't know" answers to general knowledge questions on cervical screening and risk factors of cervical cancer ( $N=379$ participants)

\begin{tabular}{|c|c|c|c|}
\hline Questions & Correct answer ${ }^{\mathrm{a}}$ & $\begin{array}{l}\text { No of correct } \\
\text { answers (\%) }\end{array}$ & $\begin{array}{l}\text { No of "don't know" } \\
\text { answers (\%) }\end{array}$ \\
\hline \multicolumn{4}{|l|}{ Knowledge of cervical screening and cancer } \\
\hline I. I'm too old to need cervical screening & Disagree & $376(99.2)$ & $0(0)$ \\
\hline $\begin{array}{l}\text { 2. Cervical screening can detect abnormal cell } \\
\text { changes in the cervix, they become cancerous }\end{array}$ & Agree & $232(6 \mid .2)$ & $0(0)$ \\
\hline $\begin{array}{l}\text { 3. Cervical screening is not necessary } \\
\text { once women have reached menopause }\end{array}$ & Disagree & $205(54.1)$ & I8 (4.7) \\
\hline $\begin{array}{l}\text { 4. Healthy women need to have } \\
\text { regular cervical screening }\end{array}$ & Agree & $353(93.1)$ & $14(3.7)$ \\
\hline $\begin{array}{l}\text { 5. Should have cervical screening } \\
\text { soon after the first experience of } \\
\text { sexual intercourse }\end{array}$ & Agree & $284(74.9)$ & $32(8.4)$ \\
\hline $\begin{array}{l}\text { 6. If I hadn't had sex for ages, } \\
\text { I wouldn't need cervical screening }\end{array}$ & Disagree & $365(96.3)$ & II (2.9) \\
\hline $\begin{array}{l}\text { 7. Once cervical screening is } \\
\text { normal, there is no need to } \\
\text { go for more Pap smears }\end{array}$ & Disagree & $362(95.5)$ & $9(2.4)$ \\
\hline $\begin{array}{l}\text { 8. Cervical cancer can be cured } \\
\text { if detected early }\end{array}$ & Agree & $335(88.4)$ & $30(7.9)$ \\
\hline $\begin{array}{l}\text { 9. Only had one sexual partner, } \\
\text { so no need to have cervical screening }\end{array}$ & Disagree & $349(92.1)$ & $16(4.2)$ \\
\hline \multicolumn{4}{|l|}{ Risk factors for cervical cancer } \\
\hline I. Having many different sexual partners & Agree & $308(8 \mid .3)$ & $10(2.6)$ \\
\hline 2. Post-menopause & Disagree & $215(56.7)$ & $74(19.5)$ \\
\hline 3. Sexually transmitted disease & Agree & $284(74.9)$ & $68(17.9)$ \\
\hline 4. Smoking & Agree & $183(48.3)$ & $88(23.2)$ \\
\hline 5. Having sex at early age & Agree & $309(8 \mid .5)$ & $33(8.7)$ \\
\hline 6. On the pill & Disagree & $160(42.2)$ & $156(4 \mid .2)$ \\
\hline $\begin{array}{l}\text { 7. Having had a previous } \\
\text { abnormal cervical smear }\end{array}$ & Agree & $333(87.9)$ & $7(1.8)$ \\
\hline 8. Having sex without a condom & Agree & $234(6 \mid .7)$ & II (2.9) \\
\hline 9. Age 45 years or more & Disagree & $236(62.3)$ & $91(24.0)$ \\
\hline
\end{tabular}

aAnswer options: agree, disagree or don't know.

test indicated a good fit of the logistic model $\left(\chi^{2}=4.734, \mathrm{df}=8\right.$, $P=0.786)$. Nagelkertke's $R^{2}$ was 0.608 which was an index of approximation to $R^{2}$ from OLS regression.

The significant factors identified were age, education, control over their own health, and knowledge on risk factors, after controlling for all other factors in the model. Younger participants ( $\leq 37$ years), had attained tertiary education, perceived having control over their own health, and had better knowledge of risk factors were more likely to attend cervical screening.

\section{Discussion}

This study reports the determinants of cervical screening among demographic variables, knowledge on cervical screening and cancer and health perception.

In this study, females aged 37 years or younger were more likely to attend cervical screening. However, statistics in Hong Kong showed that the average age-specific incidence rate of cervical cancer increased sharply after 55 years of age with a peak at aged 65 over the period of 2003 to 2007, and the cervical cancer was the eighth most common cause of registered death in females in 2007. ${ }^{9}$ More active health promotion and education efforts should target females approaching 40 years and older.

The 3 questions most often answered correctly in the general knowledge section were:

- it has to be done routinely to be effective;

- screening was still needed even if they had not had sex for years;

- getting old was not a reason to not attend cervical screening.

However, many participants thought that once women reach menopause, cervical screening was not needed. These apparent contradicting findings showed that participants 
Table 3 Cervical screening predicted by demographic variables, general knowledge as well as knowledge of risk factors

\begin{tabular}{|c|c|c|c|c|c|c|}
\hline \multirow[t]{2}{*}{ Variables } & \multirow[t]{2}{*}{ B } & \multirow[t]{2}{*}{ SE } & \multirow[t]{2}{*}{ P-value } & \multirow[t]{2}{*}{ Odds ratio } & \multicolumn{2}{|l|}{$95 \% \mathrm{Cl}$} \\
\hline & & & & & Lower & Upper \\
\hline \multicolumn{7}{|l|}{ Age (years) } \\
\hline $18-37$ & 0.92 & 0.45 & 0.04 & 2.52 & 1.04 & 6.11 \\
\hline 38 or above (reference group) & - & - & - & - & - & - \\
\hline \multicolumn{7}{|l|}{ Education } \\
\hline Tertiary & 2.20 & 0.57 & $<0.001$ & 8.9 & 2.9 & 27.4 \\
\hline Secondary or less (reference group) & - & - & - & - & - & - \\
\hline \multicolumn{7}{|l|}{ Income } \\
\hline$\$ 20,000$ or above & 0.94 & 0.46 & 0.04 & 2.55 & 1.03 & 6.32 \\
\hline Under $\$ 19,999$ (reference group) & - & - & - & - & - & - \\
\hline \multicolumn{7}{|l|}{ Health status } \\
\hline Healthy & 0.87 & 0.38 & 0.02 & 2.40 & 1.13 & 5.06 \\
\hline Average or not healthy (reference group) & - & - & - & - & - & - \\
\hline \multicolumn{7}{|l|}{ Control of health } \\
\hline Yes & 1.19 & 0.40 & 0.003 & 3.30 & 1.52 & 7.16 \\
\hline No (reference group) & - & - & - & - & - & - \\
\hline \multicolumn{7}{|l|}{ Concern about family members/relatives' health } \\
\hline Yes & 0.20 & 0.67 & 0.77 & 1.22 & 0.33 & 4.51 \\
\hline No (reference group) & - & - & - & - & - & - \\
\hline \multirow{2}{*}{\multicolumn{7}{|c|}{$\begin{array}{l}\text { Health behavior influenced by family members/ } \\
\text { relatives' health }\end{array}$}} \\
\hline & & & & & & \\
\hline Yes & -0.45 & 0.49 & 0.36 & 0.64 & 0.24 & 1.68 \\
\hline No (reference group) & - & - & - & - & - & - \\
\hline General Knowledge & 0.44 & 0.13 & 0.001 & 1.55 & 1.20 & 2.02 \\
\hline Knowledge of Risk Factors & 0.33 & 0.12 & 0.004 & 1.39 & I.II & $\mathrm{I} .74$ \\
\hline
\end{tabular}

might define menopause as an indicator of being "old enough" to be spared from cervical screening. Education on menopause and screening should be emphasized by doctors and nurses engaged in health-promoting activities.

Our findings also showed that participants were aware of the importance of having regular screening and a healthy lifestyle. However, quite a number of participants did not have accurate knowledge on risk factors and had a higher chance of failing to attend cervical screening. Such knowledge deficits probably explain why a significant number of women do not take advantage of cervical screening even though its efficacy is well known. These results also lend support to a recent qualitative study among African Americans which found that personal beliefs on screening, perception of vulnerability, and providing correct information might increase screening rates. ${ }^{21}$

The majority of participants correctly identified that having a previous abnormal cervical smear was one of the risk factors. The next most commonly identified risk factors were: having sex at early age; many different sexual partners; and sexually transmitted disease. This finding was somewhat different from reports in the United Kingdom in which only $14 \%$ of the population sample were aware of a link between cervical cancer and sexual transmission. ${ }^{22}$ Another qualitative study on women who took part in human papillomavirus
(HPV) testing also found that many participants did not recognize the link between cervical cancer and sex or sexually transmitted disease. ${ }^{23}$ Authors in those earlier studies conjectured that generally women were aware of the link between cervical cancer and sexual activity but did not clearly conceptualize the linkage between cervical cancer and HPV. They thus emphasized the role of healthcare providers in providing clear and consistent information of the sexually transmitted nature of cervical cancer.

The findings in this current study agreed with Kemm and Close's concept of internal locus of control. ${ }^{24}$ Most of the participants $(71.5 \%)$ perceived they have control of their health, which concurred with the high cervical screening. This group of women is more likely to take the initiative to engage in health-promoting activities such as cervical screening.

Our findings also supported the health belief model. Women's knowledge on cervical cancer and risk factors affected their perception of the severity of illness and their own susceptibility to it. Such knowledge was shown to be significantly related to their engagement in screening. Health care providers need to take into account women's knowledge and health perception when developing a cervical screening program. Accurate information must be readily available to women to increase their knowledge, especially on the risk factors associated with cervical cancer, to guide them on 
the importance of regular screening. Health professionals also need to further explore women's perceived ability to their control health and the effect on changing their beliefs of clearer information on the treatability and significant reduction in mortality and morbidity with early detection.

Women educated to higher level are more likely to have a better knowledge of cervical screening and cervical cancer, leading to their participation in cervical screening. Women with a higher level of education are more likely to gather new information by themselves or have a faster channel to reach up-to-date information. More active promotion strategies ought to be channeled through media that are appropriate to reach women with less education. Publicity through different means should be considered, such as TV, radio commercials and newspapers. Health education through trained lay persons in community centers could also be considered as this has been reported to be an effective method in several studies. ${ }^{25-27}$

This study has limitations on the design and sampling. It was a cross-sectional study with some longitudinal data for identifying prediction of screening at follow-up. There were a number of issues where this sampling methodology could be improved:

- Participants were recruited with convenience sampling and showed to have higher percentage with tertiary education compared to the general populations which raises some questions about generalizing these findings to the greater Hong Kong population.

- Screening was self-reported data without comparison to any objective medical records and thus the identified factors may be different from those related to the actual cervical screening.

- The questionnaires did not assess participants' knowledge on human papilloma virus which was important information relating to cervical screening.

\section{Conclusion}

The study identifies that the lack of knowledge particularly on risk factors of cervical cancer and the importance of perceived control over health are significant factors influencing cervical cancer screening among Chinese.

This study can contribute to the development of a multistrategy health program that will take into account women's perceptions of cervical screening and cancer and emphasize a non-stigmatizing approach to encourage Chinese women to attend cervical screening.

Additional studies empowering women's perception of control over their health are recommended.
The role of nurses in cervical screening programs needs to be further explored as public health nurses are commonly the ones who take smears. ${ }^{28}$ Women need to accept the correct concept at an earlier stage, thus normalizing the behavior of taking part in health-promoting activities such as cervical screening.

\section{Disclosure}

The authors report no conflicts of interest in this work.

\section{References}

1. World Health Organization. Preparing for the Introduction of HPV Vaccines: Policy and Programme Guidance for Countries. Geneva: World Health Organization; 2006.

2. Youngkin EQ, Davis MS. Women's Health: A Primary Care Clinical Guide. 3rd ed. Upper Saddle River (NJ): Pearson Prentice Hall; 2004.

3. World Health Organization. Comprehensive Cervical Cancer Control: A Guide to Essential Practice. Geneva: World Health Organization; 2006.

4. Berg AO. Screening for cervical cancer: recommendations and rationale. Am J Nurs. 2003;103(11):101-109.

5. Lee EE, Fogg L, Menon U. Knowledge and beliefs related to cervical cancer and screening among Korean American Women. West J Nurs Res. 2008;30(8):960-974.

6. Sairafi MA, Mohamed FA. Knowledge, attitudes, and practice related to cervical screening among Kuwaiti women. Med Princ Pract. 2009; $18: 35-42$.

7. Ponten J, Adami HO, Bergstrom R, et al. Strategies for global control of cervical cancer. Int J Cancer. 1995;60:1-26.

8. Oscarsson MG, Benzein EG, Wijma BE. Reasons for non-attendance at cervical screening as reported by non-attendees in Sweden. J Psychosom Obstet Gynaecol. 2008;29(1):23-31.

9. Cervical Screening Programme: Statistics and Reports. Hong Kong: Department of Health. [Online]. 2008 [cited 2010 Feb 25]. Available from: URL http://www.cervicalscreening.gov.hk/english/sr/sr_ statistics_ccsc.html.

10. Cervical Screening Programme: Evidence for organized screening programme. Hong Kong: Department of Health. [Online]. 2008 [cited 2010 Feb 25]. Available from: http://www.cervicalscreening.gov. hk/english/about/abt_evidence.html

11. Eaker S, Hans-Olov A, Par S. Reasons women do not attend screening for cervical cancer: a population-based study in Sweden. Prev Med. 2001;32:482-491.

12. McMullin JM, Alba ID, Chavez LR, Hubbell FA. Influence of beliefs about cervical cancer etiology on pap smear use among Latina immigrants. Ethn Health. 2005;10(1):3-18

13. Twinn $\mathrm{S}$, Cheng F. Increasing uptake rates of cervical cancer screening amongst Hong Kong Chinese women: the role of the practitioner. $J A d v$ Nurs. 2000;32:335-342.

14. Gupta A, Kumar A, Stewart DE. Cervical cancer screening among South Asian women in Canada; the role of education and acculturation. Health Care Women Int. 2002;23(2):123-134.

15. Cervical Screening Programme: Screening Policy. Hong Kong: Department of Health. [Online]. 2008 [cited 2010 Feb 25]. Available from: http://www.cervicalscreening.gov.hk/english/about/abt screening.html

16. Ajzen I, Fishbein M. Understanding Attitudes and Predicting Social Behavior. Englewood Cliffs (NJ): Prentice Hall; 1980.

17. Hochbaum GM. Public participation in medical screening programs: A sociopsychological study. (Public Health Service Publication No. 572). Washington, DC: US Government Printing Office; 1958. 
18. Seow A, Wong ML, Smith WCS, Lee HP. Beliefs and attitudes as determinants of cervical cancer screening: a community-based in Singapore. Prev Med. 1995;24:134-141.

19. Twinn S, Shiu ATY, Holroyd E. Women's knowledge about cervical cancer and cervical screening practice: a pilot study of Hong Kong Chinese women. Cancer Nurs. 2002;25:377-384.

20. Holroyd E, Twinn SF, Shia AT. Chinese women's experience and images of the Pap smear examination. Cancer Nurs. 2001;24:68-75.

21. Ackerson K, Pohl J, Low LK. Personal influencing factors associated with pap smear testing and cervical cancer. Policy Polit Nurs Pract. 2008;9(1):50-60.

22. Waller J, McCaffery $\mathrm{K}$, Wardle J. Beliefs about the risk factors for cervical cancer in a British population sample. Prev Med. 2004;38: $745-753$.

23. Waller J, McCaffery K, Nazroo J, Wardle J. Making sense of information about HPV in cervical screening: a qualitative study. Br J Cancer. 2005;92:265-270.
24. Kemm J, Close A. Health Promotion: Theory and Practice. London: Macmillan Press; 1995.

25. Nguyen TT, McPhee SJ, Gildengorin G, et al. Papanicolaou testing among Vietnamese Americans: results of a multifaceted intervention. Am J Prev Med. 2006;31(1):1-9.

26. Hansen LK, Feigl P, Modiano MR, et al. An educational program to increase cervical and breast cancer screening in Hispanic women. Cancer Nurs. 2005;28(1):47-53.

27. Lam TK, McPhee SJ, Mock J, et al. Encouraging Vietnamese-American women to obtain pap tests through lay health worker outreach and media education. J Gen Intern Med. 2003;18:516-524.

28. Hong Kong Department of Health. Prevention and Screening of Cervical Cancer. Topical Health Report No. 4. 2004;4:1-62. Available from: http://www.chp.gov.hk/files/pdf/grp-THR-report4-en-20050407.pdf

\section{Publish your work in this journal}

The International Journal of Women's Health is an international, peerreviewed open-access journal publishing original research, reports, reviews and commentaries on all aspects of women's healthcare including gynecology, obstetrics, and breast cancer. Subject areas include: Chronic conditions (migraine headaches, arthritis, osteoporosis);
Endocrine and autoimmune syndromes; Sexual and reproductive health; Psychological and psychosocial conditions. The manuscript management system is completely online and includes a very quick and fair peer-review system. Visit http://www.dovepress.com/ testimonials.php to read real quotes from published authors. 